\title{
Assessment of Firefighters' needs for personal protective equipment
}

\author{
Huiju Park ${ }^{1 *}$, Juyeon Park², Shu-Hwa Lin ${ }^{3}$ and Lynn M Boorady ${ }^{4}$
}

\author{
* Correspondence: \\ hp347@cornell.edu \\ ${ }^{1}$ Department of Fiber Science and \\ Apparel Design, Cornell University, \\ 131 Human Ecology Building, 37 \\ Forest Home Dr., Ithaca, NY 14853, \\ USA \\ Full list of author information is \\ available at the end of the article
}

\begin{abstract}
This study performed focus group interviews with 54 firefighters in four states in the United States to assess the needs for design of firefighters' personal protective equipment. Firefighters' responses indicate three major issues to be considered for improved mobility, comfort and safety: 1) consideration of human factors, 2) sizing and fit, and 3) integrity of protection in the interface between protective equipment and turnout ensemble. Ergonomic design issues were identified through firefighters' responses about their limited mobility of the head and arms while wearing helmet and self-contained breathing apparatus (SCBA), restricted access to coat pockets, back pain and soreness while wearing SCBA. Sizing and fit issues such as the excessive length and bulkiness of glove fingers were identified as a major concern regarding fire gloves resulting in limited mobility and dexterity, negatively effecting firefighters' work efficiency and safety. The integrity of protection in the interface between turnout ensemble, gloves and boots was reported as an important consideration for firefighter comfort, mobility and protection against heat hazards. Possible design solutions were also discussed.
\end{abstract}

Keywords: Firefighters; Protection; Equipment; Wearability; Comfort; Mobility; Size; Fit

\section{Introduction}

Firefighting is one of the most dangerous occupations that require intensive physical work in hazardous environment (Coca et al. 2010). US Firefighters are required to wear turnout ensemble (i.e., protective coat and pants), and other personal protective equipment (PPE) such as helmet, gloves, boots and a self-contained breathing apparatus (SCBA) certified by NFPA (National Fire Protection Association) 1971 and 1981 standards (Figure 1). These items of firefighters' protective system have been designed to provide protection against multiple hazards such as thermal threats (e.g. exposure to flame and excessive heat), toxic gas inhalation, and physical injuries (e.g. cuts, collisions, punctures, slips, falls etc.). So far, the focus of most studies on the firefighters' protective system has been on thermal protection, which combined with advances in material technology during the past decade, has greatly decreased burn injuries (Boorady et al. 2013). However, literature reports that the efforts to improve thermal protection have inevitably increased the weight and bulkiness of the firefighters' protective system, hence, significantly compromising firefighters' mobility and comfort (Adams \& Keyserling 1993; Boorady et al. 2013). Sobeih et al. (2006) and Dorman (2007) determined that wearing heavy and bulky turnout clothing caused restricted body

\section{黛 Springer}

(c) 2014 Park et al.; licensee Springer. This is an Open Access article distributed under the terms of the Creative Commons Attribution License (http://creativecommons.org/licenses/by/4.0), which permits unrestricted use, distribution, and reproduction in any medium, provided the original work is properly cited. 


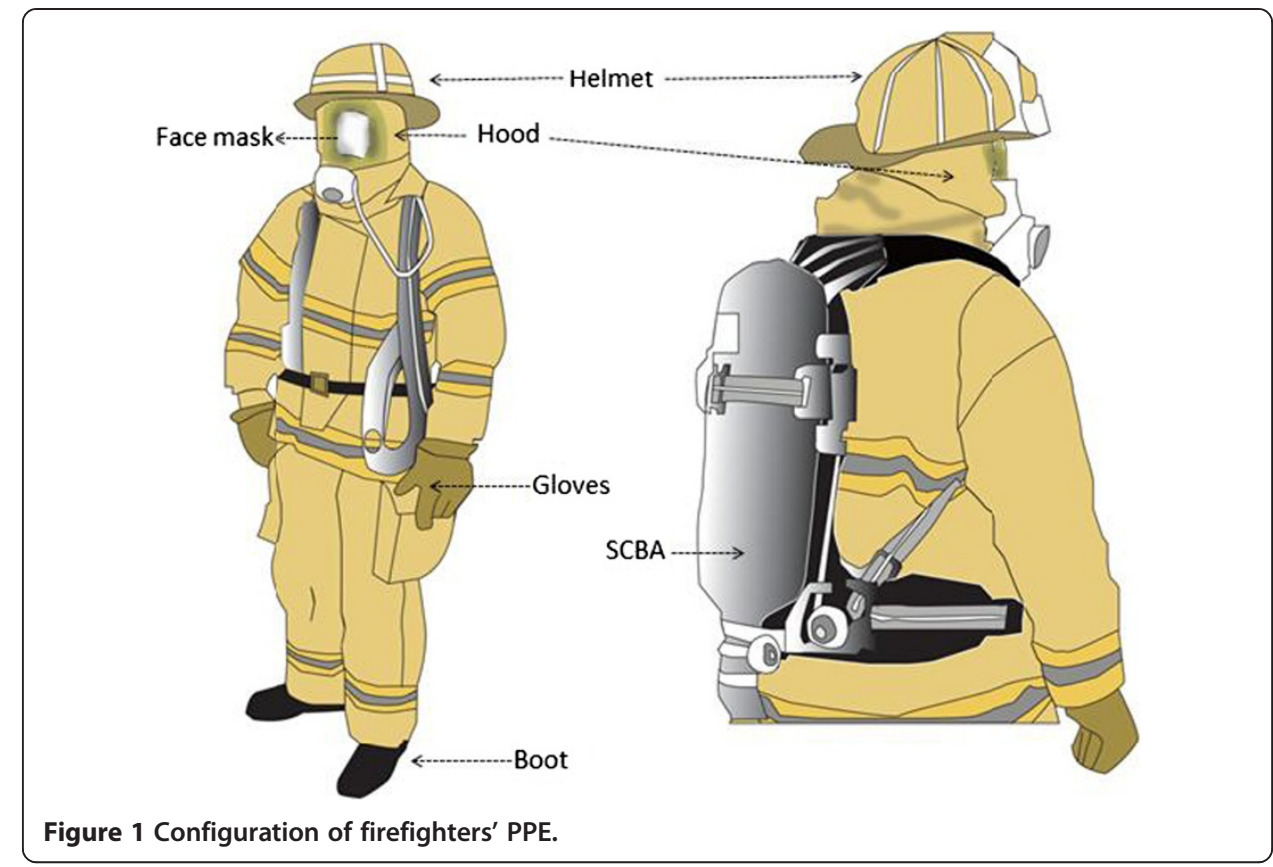

movement, leading to a number of firefighters' injuries on unfavorable fire grounds. Coca et al. (2010) also identified a decrease in range of motion at the neck and ankle while wearing turnout ensemble. Moreover, SCBA and boots have also been reported as a cause to impair body balance and musculoskeletal injuries. Carrying a SCBA (weighing 9-13 kg on average) on their back disturbs firefighters' body balance during motion by changing their center of mass, which is a major contributor to fall injuries (Helneman et al. 1989). Additionally, Park et al. (2010) reported that an increase in weight of SCBA elevates the risk of fall and slip injuries. Wearing heavy protective boots, which can weigh up to $4.4 \mathrm{~kg}$, was known to trigger rapid fatigue as evidenced by approximately nine times greater metabolic rate per unit mass, compared to SCBA (Taylor et al. 2011). A previous study by Neeves et al. (1989) also concluded that wearing heavier boots causes more physical burden due to less efficient leg movement during firefighter's job-related tasks.

While the aforementioned physiological and biomechanical investigations examine the impact of firefighters' protective system on their mobility and work efficiency providing quantitative evidence, investigation about firefighters' input and needs for protective systems is also an important element in improving the design of their protective system. (Huck 1988) and Akbar-Khanzadeh et al. (1995) claimed that increased wearability and proper usage of the protective clothing system can be achieved only when human factors and user input are included in the design process. The two studies further stated that lack of an understanding of user perception and demand can result in improper or no use of the protective system. Boorady et al. (2013) and Sinden et al. (2013) claimed that firefighters' perception about the performance of their turnout clothing should be considered to improve the design of their protective system. The two studies suggested that designers should take into account the wearers' gender specific issues (e.g., body shape and size) and human factors in their job-related tasks and also upheld that female firefighters are more vulnerable to ill-fitting protective clothing. 
Although a few studies investigated firefighters' perception about their turnout clothing, there is no study that investigated their equipment such as helmet, gloves, boots, and SCBA. Considering that the equipment is a critical component of firefighters' protection for their extremities and their head, as well as an essential interface between their body and their job environment, it is imperative to understand user experiences and needs for further design improvements. Moreover, a recent survey of 951 firefighters conducted by National Institute for Occupational Safety and Health reported firefighters' perceived impact of protective equipment on their work efficiency and comfort (Hsiao et al. 2014). Based on the research gap and the actual need for improvement, this study assessed firefighters' perception of their needs for protective equipment (gloves, boots, SCBA and helmet) through a survey and focus group interview (FGI). FGI has been used in the area of social science because it provides an indepth understanding of research questions by acquiring substantial data from participants (Esterberg 2002). FGI allows participants to speak in depth about the given topics, while they could articulate their perception and ideas independently (Boorady et al. 2013).

\section{Methods}

Semi-structured FGIs were performed at fire stations in four different geographical locations in the Unites States. A total of six fire stations participated in this study. The settings of the geographical locations varied from urban to rural and from the Northeastern region to the Western Pacific region. Approval of the Institutional Review Board (IRB) was obtained through the participating universities' IRB offices. Prior to the focus group interviews, a short survey was administered to firefighters. The survey inquired 1) the participant's demographic information (e.g., age and gender), 2) type of commitment to the fire service and duration of the service, and 3) experience of injuries. The survey also included preliminary questions about firefighters' perception of boot and glove performance, considering the significant impact of those two items in extremity protection. These questions were developed by the researchers based on the review of NFPA standards combined with the literature review of firegear studies. The questions concerning the boots inquired the participants' satisfaction relative to 12 properties of the boots, using 5 point Likert-type scale (1: very dissatisfied - 3: neutral-5: very satisfied). The 12 properties included fire/flame protection, hot splash/steam protection, water-proofness, puncture/impact protection, durability, chemical protection, thermal comfort (dryness and comfortable temperature), cushioning, traction quality, structural foot support, stability and flexibility in motion. The questions related to glove performance inquired about firefighters' satisfaction with fire/flame protection, water-proofness, thermal comfort, grip, and dexterity. The entire FGIs were audiotaped for transcription and data analysis. A total of 23 survey questions were asked as summarized in Table 1.

The questionnaire for the FGI consisted of six items (Table 2), asking firefighters' perception about each item of fire gear (boots, gloves, helmet and SCBA) and potential needs for improvement. The researchers followed up with additional questions when the participants' responses required further information or clarification.

A total of 54 firefighters (48 male firefighters and 6 females, age: $34.8 \pm 11.1$ years), recruited from the four different U.S. locations, participated in the FGI (Table 3). Firefighter 
Table 1 Survey questions

\begin{tabular}{ll}
\hline Items & Questions \\
\hline Partic ipants' demographic information & Age \\
Type of commitment to fire service & Gender \\
& Commitment type (volunteer vs professional) \\
Injury & Year of fire service \\
& Types of injury \\
Satisfaction level with fire boots & Frequency of injury \\
Satisfaction level with fire gloves & 12 key performance properties \\
\hline
\end{tabular}

participants had $9.8 \pm 8.5$ years of experience of fire service and detail is shown as follows: 5 participants ( $<3$ years), 10 participants (3-6 years), 6 participants (7-9 years), and 10 participants (more than 10 years).

\section{Data analysis and results}

Descriptive statistics of participants' satisfaction with their fire gear and frequency of injuries were calculated to identify the potential area of improvement in performance of the fire gear. Firefighters' comments from the FGI were coded using the interpretive thematic analysis method, which allowed grouping of the responses into overarching themes with related issues.

\section{Survey}

Fire gloves

The mean value of firefighters' responses about the performance of fire gloves revealed low satisfaction with water-proofness (mean: $1.9 \pm 1.1$ ), grip (mean: $2.5 \pm 0.9$ ), dexterity (mean: $1.8 \pm 0.9$ ) and thermal comfort (mean: $2.9 \pm 0.7$ ). However, firefighters' satisfaction with fire/flame protection was relatively higher (mean: $3.6 \pm 1.03$ ) (Figure 2).

\section{Turnout boots}

Firefighters' responses about satisfaction with cushioning (mean: $2.8 \pm 1.2$ ), structural foot support (mean: $2.5 \pm 1.3$ ) and flexibility in motion (mean: $3.0 \pm 1.2$ ) indicated low mean values ( $\leq 3$ : neutral), while the other nine properties regarding the levels of protection, durability and thermal comfort showed relatively higher satisfaction scores

\section{Table 2 Questions for focus group interviews}

\begin{tabular}{ll}
\hline Item & Question \\
\hline Experience & Explain your experience wearing [the name of each item of protective equipment]. \\
Impact & What do you think about the impact of wearing [the name of each item of protective \\
& equipment] on your protection, work efficiency, mobility, comfort and safety? \\
Satisfaction & How satisfied are you with the size and fit of your [the name of each item of \\
& protective equipment]? If you are not satisfied, explain why in detail. \\
Interface & What do you feel about the interface between [the name of each item of protective \\
& equipment] and the turnout ensemble (or other items close to/connected with the \\
Size selection & How do you find the right size? \\
Suggestion & Do you have any constructive feedback for improvement of the design? \\
\hline
\end{tabular}


Table 3 Focus group interview participants' information

\begin{tabular}{llll}
\hline Site & Professional/Volunteer & Geographical region & Total \# of participants \\
\hline 1 & $2 / 7$ & Northeast & 9 \\
2 & $10 / 0$ & West & 10 \\
3 & $10 / 0$ & West & 10 \\
4 & $11 / 0$ & Pacific & 11 \\
5 & $6 / 0$ & Pacific & 6 \\
6 & $0 / 8$ & Northeast & 8 \\
\hline
\end{tabular}

(Figure 3). The highest satisfaction levels were associated with water-proofness (mean: $4.4 \pm 0.7$ ) and fire/flame protection (mean: $4.2 \pm 0.7$ ).

\section{Reported injuries}

Many firefighters indicated wearing ill-fitting boots especially bulky rubber boots caused blisters $(\mathrm{n}=21)$ on the calves, around the boot collar and plantar foot (Table 4).

Muscle pains $(n=20)$ in the back, shoulders, back of the neck and knee were also reported as frequent injuries. This may be related to the fact that firefighters carry heavy SCBA or tools while working in bulky turnout ensemble and equipment that may restrict or alter their normal body movement. More than ten firefighters reported they experienced stumbles, slips, falls, and ankle sprains as they worked on unfavorable fire grounds or confined spaces (Table 4).

FGI

Fire gloves

Firefighters reported poor dexterity as the biggest concern with gloves, and it was due to oversized glove design with multi-layered bulky structure. They reported that the poor dexterity and limited grip hindered them from working with tools. For example, a female firefighter accounted as such: "Dexterity is the big issue, especially if they're smaller hands. Like for me, my hands are really small so it's hard to find gloves that fit really good (Site \#2)." Male firefighters also indicated the dexterity issue associated with gloves: "The fit, the way they form the fingers they are just too fat, there's too much material where is the ability of protection and the ability to grip right, there's just a lot of extra bulk on the fingertips (Site \#1)." Another male firefighter described his experience with gloves in a specific firefighting task: "We have to tie a knot. If you're working with extra this much on the end of each finger, trying to dexterously feed up a rope through a

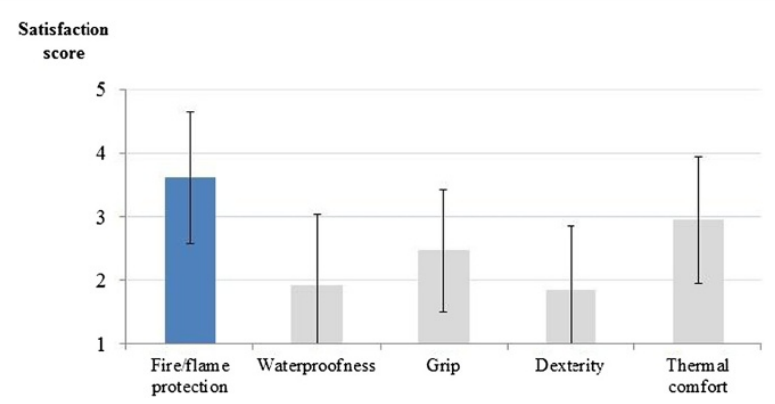

Figure 2 Mean values of firefighters' satisfaction with 5 properties of fire gloves. 


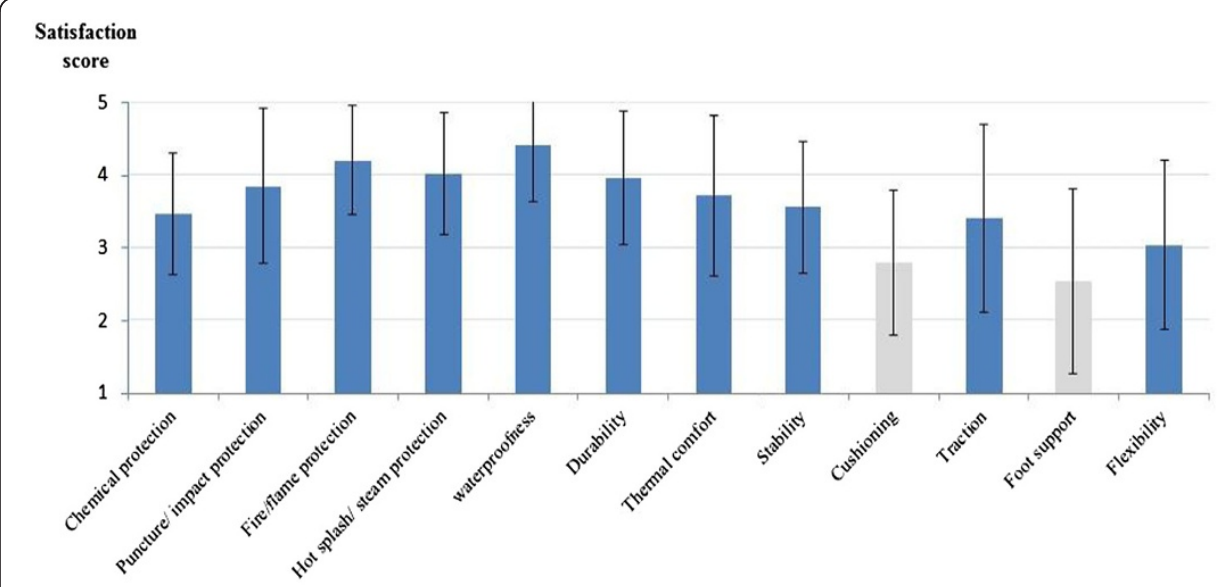

Figure 3 Mean values of firefighters' satisfaction with 12 properties of fire boots.

knot, it's very difficult (Site \#6)." Most firefighters expressed the stiffness of material had made gloves hard to crap and pick small devices. Very often, firefighters cannot even operate a phone to communicate each other due to thickness and stiffness materials of gloves.

Challenging tasks with gloved hands include a majority of essential movements requiring hand motions such as using a walkie-talkie, carrying, holding and using tools or hoses etc. In particular, holding a hose (approximately $45 \mathrm{~kg}$ of pressure at the tip) with gloved hands is very challenging due to poor grip in the palm and fingers. A male firefighter elucidated the situation as such: "There's almost no grip on my palm right now. Even though it's resting on my palm, all the grip is in the fingers. I can't grip the hose with my gloves. I grip it with my body and my arm. If I try to hold it just with my glove, it will slide (Site \#6)."

The challenge resulted from oversized gloves seemed more obvious to small-handed firefighters, especially females, prompting them to use better-fitting work gloves (lacking fire and flame protection) for non-fire related duties. Firefighters also reported that donning the wet gloves once they had been taken off was difficult because the gloved fingers tended to turn inside out when their hands were wet, thus making it hard to

Table 4 Reported injuries

\begin{tabular}{lcccc}
\hline & \multicolumn{4}{c}{ Number of incidences } \\
\cline { 2 - 5 } Injuries & $\mathbf{1 - 5}$ times & $\mathbf{6 - 1 0}$ times & Over $\mathbf{1 0}$ times & Sub-total \\
\hline Blisters & 13 & 4 & 4 & 21 \\
Muscle pain & 9 & 1 & 11 & 20 \\
Stumbles & 8 & & 7 & 18 \\
Slips & 8 & 3 & 15 \\
Falls & 10 & & 13 \\
Ankle sprains & 10 & & 10 \\
Bruises & 3 & & 1 \\
Minor cuts & 1 & & 1 \\
Smashing & 1 & & 1 \\
Scrapes & 1 & & 1 \\
Burns & 1 & & 1 \\
Electrically conducted & 1 & & \\
\hline
\end{tabular}


rearrange them. This seemed to render firefighters hesitant to take off their wet gloves despite thermal discomfort and loss of grip. Such firefighters' behavior in the field could cause increased risk of burn injury from quicker heat transfer in the wet gloves compared to dry gloves, as described in the following account: "My hands sweat from doing stuff with water and then I pull the glove off and the whole lining comes off with my hand. And I can't get it back in", "If you were holding a hose and you get a lot of splash back on your gloves, you gloves can get wet and be very hot right away (Site \#6)." Another account also illustrated the firefighting risk factor associated with wet gloves: "Due to the poor dexterity, firefighters often feel temptation to take gloves off. For example, when you need to use axes and your gloves get wet, think about it... Using an ax and wearing slippery gloves is not a good match (Site \#6)." Additionally, a wide range of glove sizes offered by manufacturers were also reported as a confusing factor in finding the right size, as a firefighter asserted like: "You get a box of gloves and you just try them on until you find one (Site \#6)."

A few female firefighters indicated that working with heavy tools while wearing oversized gloves imposes more physical challenges to them. "Holding it (the chainsaw) up is such a pain in the butt because your fingers are so thick in the gloves. Starting that chainsaw is very hard for me. I have to literally sit on the chainsaw and pull like this to get it started (Site \#6)."

\section{Turnout boots}

Firefighters reported that wearing turnout boots changes their walking pattern and the extent of the change is greater for rubber boots than leather boots. Firefighters described their gait, while wearing turnout boots like: "You have to have extra kick in your boot." "You can't really run (Site \#6)." In particular, firefighters reported various reasons for discomfort when wearing rubber boots, including poor fit, low resistance against abrasion (Figure 4), heaviness, bulkiness, stiffness and difficulty in finding the right size.

Furthermore, firefighters reported that poor fit is a major reason for changes in their walking patterns and this negatively impacts on their safety on the fire ground. They also indicated that they experienced frequent fall-offs of the rubber boots due to the poor fit, while ascending or descending during ladder operations, stair climbing, and getting on/off the fire engine. Firefighters additionally accounted their frequent experiences of blisters due to the increased rubbing between their feet and boots resulting from the poor fit. Moreover, they reported that the stiffness of rubber often caused chaffing injuries to their calves, as a female firefighter described as following: "I had two pairs of thick socks and I always had blisters in the rubber ones (Site \#1)." Additionally, firefighters reported that wearing rubber boots during winter leaves their feet vulnerable to cold injuries and likely causes loss of traction on the slippery fire ground: "They (rubber) didn't keep your feet warm, I remember being at a fire in the winter -my feet were frozen (Site \#1)." "When it's really cold, the rubber boot freezes up so you don't have good traction (Site \# 2)."

Firefighters showed a strong preference for leather boots due to the following reasons: a snugger fit, lighter weight, better flexibility, ankle support, tactile sensation on the ground, more comfortable foot motion and easier size choice than rubber boots. "I find it's better flexibility when your foot is bent in the leather boots, you couldn't get that flexing. Where you are planting your foot of pushing off, the more pliable the material the better it's going to be. (Site \#1)," "When I got my leather boots I felt like I didn't have to be as careful as I moved my leg because my boots weren't going to fly off anymore 


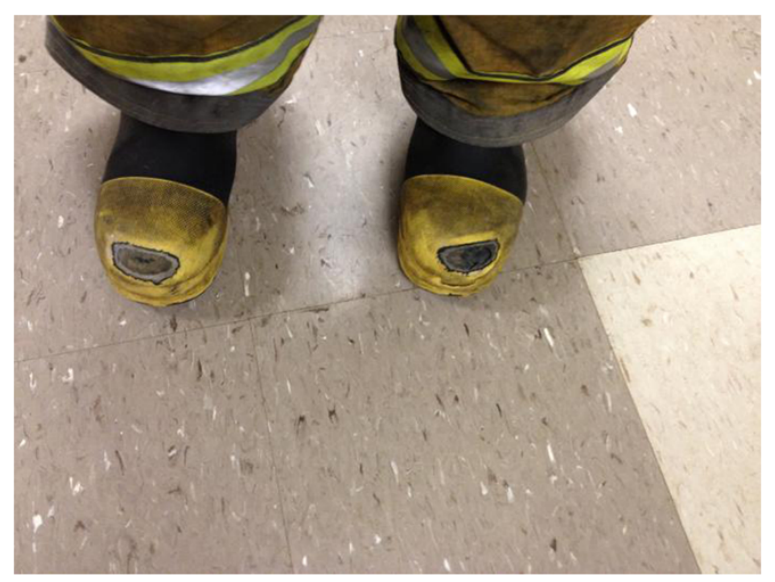

Figure 4 Worn out toe cap due to frequent friction on the ground while crawling.

(Site \#6)." Some firefighters also described their positive experiences with leather boots, in comparison with rubber boots: "I've used rubber boots for years, and what I find with the leather ones is you have better tactile sensation when you're climbing a ladder you can feel the ladder better (Site \#3)."

\section{$S C B A$}

Firefighters predominantly indicated their experiences of discomfort wearing SCBA, because of restricted movement of the head and the arm, soreness on the shoulder, and back pain. Specifically, they often experienced restricted motion of the head, especially while looking up and around because the back brim of their helmet hits the top portion of the air pack (Figure 5). They indicated that wearing SCBA had a greater impact on firefighters whose height is relatively short, because they carry the same air pack but have a shorter torso than their taller colleagues; Shorter firefighters indicated that they could not place the SCBA further down on the back, as did their taller colleagues to prevent the back brim of the helmet from hitting the top portion of the SCBA for improved neck mobility.

The following accounts explained how their physical profile, especially the torso size, affects neck mobility and visibility of firefighters in the field, in relation to SCBA: "You know a lot of time it restricts your ability to look up. So, just depending on how tall you are and where your air pack comes to, on your back. Looking up either when you're walking or crawling can be an issue (Site \#2).", "I find a lot of restriction in the shoulders- overhead work especially with the SCBA (Site \#1)." In addition, some firefighters pointed out that the stiff and oversized neckline of the turnout coat is an additional reason for their limited neck mobility. Firefighters mentioned that wearing SCBA restricts their arm movement considerably: "You can't reach up - your jacket sort of moves with you but if you've got the SCBA buckled around you (Site \#1)." "Sometimes the straps do limit your mobility and your access to different things like when you have to reach over head (Site \#6)." Another common response was a hindrance in accessing the pockets because the SCBA straps tend to block access to pockets which likely impedes firefighters from reaching tools in the pockets when they need to use them: "I don't think a lot of people put the stuff in the coat pockets because it gets tangled up with your SCBA pack. Most people just use their leg pockets (Site \#3)." 


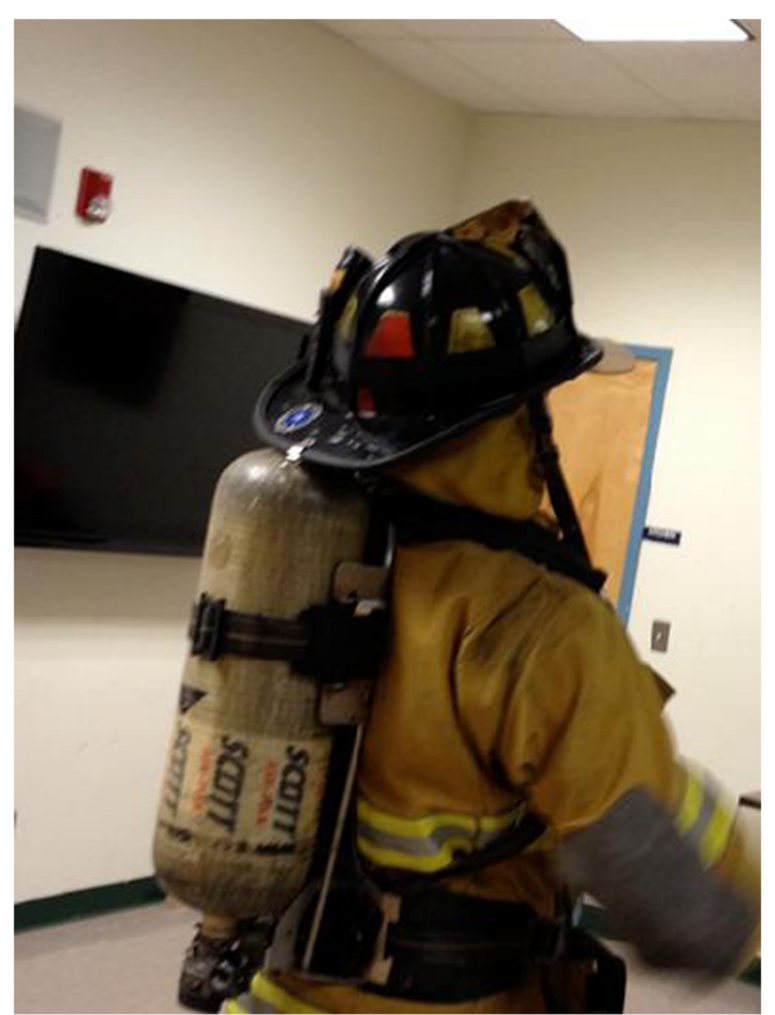

Figure $\mathbf{5}$ Limited mobility due to physical conflicts between the helmet and air pack.

Firefighters also mentioned concerns about possible injuries when they fall or slip due to the heavy SCBA on their back, as illustrated in the account: "If you fall on your back there's potential to have significant injury. If you were to fall, slips on the ice and you fall flat on your back, you're probably going to hurt yourself (Site \#2)."

\section{Helmet, face mask and hood}

Firefighters reported discomfort from ill-fitting face masks when they were worn with the helmet as such: "When I have my mask on, I can't push my helmet down where its comfortable so I feel like it's sitting up higher on my head and I have to crank my chin strap down to keep it from falling off and it just doesn't marry up well on my face, and it's probably because my face is smaller (Site \#2)." Some firefighters also reported the itchiness of the hood, especially when it is wet.

\section{Interface between equipment and turnout ensemble}

Firefighters reported the interface between equipment and turnout ensemble as an area of improvement for enhanced protection and mobility. Although each individual item of PPE may be well designed to meet NFPA standards, combining multiple pieces of equipment together creates a bulky turnout ensemble. Firefighters also need to wear their turnout ensemble on top of daily clothing, and it appears to add additional bulkiness and inconvenience to the clothing interface, especially where gloves and boots are connected with the turnout ensemble. This situation causes mobility restrictions, discomfort, poor-fitting and body exposure to heat hazards during motion, as the following account states: "They're designed individually and individually they are great, but 
together all these layers stack up and they're not designed to work together necessarily. If somebody could have some continuity of thought across each layer, which would help bulking up in the kind of bulky areas (Site \#2)."

Evidently, firefighters are concerned about the exposure of their lower limbs to heat hazards while they are crawling, as they frequently experience their pants riding up above the boots, exposing their calves to heat hazard: "When we're crawling that boot design is cut a little bit lower so when we'd crawl, our pants would ride up, so then they got exposed areas and you know there's nothing to keep that from happening (Site \#2)." "When I would be doing a search my pants would ride up over my boots and expose skin and then when I would stand up to go from a crawling to a standing position my pants would hang up on the tops of my boots (Site \#3)." Excessive bulkiness in the interface between the sleeve and gloves was also reported as an area in need of improvement: "They're really thick cuffs so nobody sticks them underneath because then you've got more mobility issues of another layer of material (Site \#2)." Major issues that were discussed at the FGI were summarized in Table 5.

\section{Discussion and conclusions}

Input from firefighters in this study, related to their PPE, identified several areas of improvement. The three major issues that firefighters' response indicated are a) consideration of human factors, b) sizing and fit, and c) integrity of protection in the interface for improved mobility, protection and comfort.

Table 5 Summary of major considerations for improved design

\begin{tabular}{|c|c|}
\hline Items & Issues to consider improvement of design \\
\hline \multirow[t]{5}{*}{ Fire gloves } & Needs to improve dexterity \\
\hline & Oversized glove design \\
\hline & Lack of grips \\
\hline & $\begin{array}{l}\text { Confusing sizing system and inconsistency in size among } \\
\text { manufacturers }\end{array}$ \\
\hline & Potential heat hazards when gloves get wet \\
\hline \multirow[t]{4}{*}{ Turnout boots } & Change in walking pattern in turnout boots \\
\hline & Frequent fall-offs due to poor fit \\
\hline & Coldness and lack of traction of rubber boots during winter \\
\hline & $\begin{array}{l}\text { Strong preference for leather boots (snug fit, better tactile sensation } \\
\text { \& lightweight) }\end{array}$ \\
\hline \multirow[t]{5}{*}{ SCBA } & Restricted movement of the head and arms \\
\hline & Greater negative on shorter firefighters \\
\hline & muscle soreness and pain in the back and shoulder \\
\hline & Hindrance in accessing pockets of turnout coat \\
\hline & Risk of serious injury when falling \\
\hline \multirow[t]{2}{*}{ Helmet, face mask and hood } & Poor fit \\
\hline & Itching face mask when wet \\
\hline \multirow[t]{2}{*}{$\begin{array}{l}\text { Interface between equipment and } \\
\text { turnout ensemble }\end{array}$} & $\begin{array}{l}\text { Excessive bulkiness where the boots and gloves are connected with } \\
\text { turnout ensemble }\end{array}$ \\
\hline & Exposure of calf to heat hazard resulting from the pants riding up \\
\hline
\end{tabular}


Ergonomic design issues were identified through firefighters' responses about their limited mobility of the head and arms while wearing helmet and SCBA, restricted access to coat pockets, back pain and soreness while wearing SCBA. A study by Coca et al. (2010), which measured range of motion of firefighters while wearing a turnout ensemble, has also reported limited mobility around the neck area. Since this limited range of motion leads to limited vision, improving the range of motion of the neck, changing the helmet design, possibly with a smaller back brim or an entire helmet, or changing the SCBA design, will have potential to improve firefighters' safety. This will further enhance their ability to visually inspect and recognize risk factors in the field where there are a variety of hazards, especially due to damaged building structures.

Firefighters' input in this study also showed that they experience soreness in the shoulder and back, which is related to wearing SCBA. Previous studies found that wearing SCBA is positively related to loss of body balance and fall injuries on the fire ground by shifting the body's center of gravity and causing gait instability (Park et al. 2010). By wearing the SCBA (weighing about 30-40 pounds) on the back, the firefighter's center of gravity shifts upward and backward from the pelvis (original location of unloaded body). The gravity shift caused by wearing the heavy SCBA may have greater impacts on mobility to lighter-weight firefighters, since the ratio of body mass to weight of load carriage is a critical factor to fatigue increase (Marshall 1980). Similarly, the negative impact of wearing SCBA can be greater to shorter firefighters who may have less body mass as the shift of center of gravity is dominated by the additional weight and the dimensions of the air pack, relative to the body profile; taller firefighters have a relatively longer torso allowing them to lower the SCBA resulting in improved neck mobility and possibly alleviating the impact of SCBA on the shifting of the center of mass. Griefahn et al. (2003) demonstrated that lowering the weight distribution of the air pack on the back could improve firefighters' mobility and work experience. They reported that rucksack style SCBA, featuring a lower placement of the air pack and an even weight distribution throughout the back, resulted in faster task completion with less fatigue than a conventional cylindrical shaped SCBA. Based on the aforementioned ergonomic consideration and previous research, an attempt to lower the placement of the air pack may minimize the shifting of the center of gravity, as well as avert physical conflicts with the back brim of the helmet, thus improving body balance and the range of motion around the neck area in firefighters. Research and design efforts to distribute the weight of the air pack more evenly around the torso are necessary in order to alleviate back pains and muscle soreness. Park et al. (2013) study affirmed that wearing a backpack can result in chronic lumbar pain over time. Furthermore, relocating coat pockets should also be considered in order to enhance firefighter access to their tools while wearing the SCBA.

Sizing and fit issues were identified as a major concern regarding fire gloves and boots, resulting in limited mobility and dexterity, negatively effecting firefighters' work efficiency and safety. Firefighters clearly pointed out that oversized gloves significantly limit grip and dexterity, resulting in additional physical effort requirements in a variety of tasks. In our study, a commonly reported issue was the excessive length of glove fingers. These oversized gloves are a more serious issue for female firefighters compared to their male colleagues. Female firefighters tended to feel that the majority of PPE, including gloves, is designed based on male physique. Female firefighters reported that the loss of grip and dexterity from wearing oversized gloves is an extra challenge for them, and it added more stress to their relatively weak physical strength. This leads female firefighters to develop 
their own strategies to perform tasks that require using tools with oversized gloves, in order to compensate their limited physical strength, resulting in supplementary physical strain (Sinden et al. 2013). Firefighters also reported that a wide range of inconsistency in glove sizes by different manufacturers is another challenge when choosing the right size of gloves. A similar sizing and fit issue was reported regarding rubber boots in this study. Firefighters mentioned that rubber boots are oversized, leading to frequent fall off of the boots during ascending and descending movements, and also blisters due to poor fitting and stiff boot materials. This may also be related to the firefighters' frequent experience of fall injuries, ankle sprains, stumbles, slips, and blisters reported in the survey of this study. Sizing and fitting issues were also identified in respect to the face mask and helmet. The aforementioned sizing and fit issues in firefighters' PPE suggested needs for revisiting anthropometric data and re-evaluating the sizing system of PPE.

The integrity of protection in the interface between turnout ensemble and PPE (gloves and boots) was reported as an important consideration for firefighter wearing comfort and protection against heat hazards. Reducing bulkiness in the sleeve-gloves interface needs to be considered for improved comfort and wearability. Firefighters' concerns about exposing the calves due to pants' riding up above the boots while crawling indicated a need for additional research and design effort to maintain the integrity of thermal protection in the interface between the turnout ensemble and extremity protection with consideration of the interaction between the moving human body and PPE.

This study performed FGI with 54 firefighters (including only six female firefighters) and was limited to four States in the United States. Therefore, generalizing the findings of this study for the entire fire service population requires some caution. Nevertheless, the study presented practical implications and insight, both for the fire-gear industry and apparel design educators, based on user input. Future studies with a larger sample and firefighters' performance evaluation in a simulated field environment could provide additional meaningful information.

Competing interest

All authors declare that they have no competing interest in relation to this study.

Authors' contributions

HP and JP collaboratively designed the research protocol and developed research instruments and a coding scheme for data analysis. All authors carried out focus group interviews and coded data. HP drafted the manuscript and JP, $\mathrm{S}-\mathrm{HL}$ and LB participated in the revision process. All authors read and approved the final manuscript.

Acknowledgement

This research was supported in part by the Cornell University (Project No. NYC 329832), Colorado State University (COL00224), and University of Hawai'i at Mānoa (HAW00360-R), Agricultural Experiment Station funds, received from the National Institute of Food and Agriculture (NIFA) United States Department of Agriculture. Any opinions, findings, conclusions, or recommendations expressed in the publication are those of the author(s) and do not necessarily reflect the view of the National Institute of Food and Agriculture (NIFA) or the United States Department of Agriculture (USDA)

\section{Author details}

${ }^{1}$ Department of Fiber Science and Apparel Design, Cornell University, 131 Human Ecology Building, 37 Forest Home Dr., Ithaca, NY 14853, USA. ²Department of Design and Merchandising, Colorado State University, 314A Gifford Building, 1574 Campus Delivery, Fort Collins, CO 80523, USA. ${ }^{3}$ Department of Family \& Consumer Sciences, Fashion Design \& Merchandising, University of Hawai'i at Mānoa, 2515 Campus Rd., Miller 201, Honolulu, HI 96822, USA. ${ }^{4}$ Fashion and Textile Technology Department, State University of New York-Buffalo State, TECH 303,1300 Elmwood Avenue, Buffalo, NY 14222, USA. 
References

Adams, PS, \& Keyserling, WM. (1993). Three methods for measuring range of motion while wearing protective clothing: a comparative study. International Journal of Industrial Ergonomics, 12(3), 177-191.

Akbar-Khanzadeh, F, Bisesi, MS, \& Rivas, RD. (1995). Comfort of personal protective equipment. Applied Ergonomics, 26(3), 195-198.

Boorady, LM, Barker, J, Lee, Y-A, Lin, S-H, Cho, E, \& Ashdon, SP. (2013). Exploration of firefighter turnout gear; Part 1: identifying male firefighter use needs. Journal of Textile and Apparel, Technology and Management, 8(1), 1-13.

Coca, A, Williams, WJ, Roberge, RJ, \& Powell, JB. (2010). Effects of fire fighter protective ensembles on mobility and performance. Applied ergonomics, 41(4), 636-641.

Dorman, LE. (2007). PhD Thesis, The Effects of Protective Clothing and its Properties on Energy Consumption During Different Activities. @ Lucy Ellen Dorman.

Esterberg, KG. (2002). Qualitative Methods in Social Research. Boston: McGraw-Hill.

Griefahn, B, Künemund, C, \& Bröde, P. (2003). Evaluation of performance and load in simulated rescue tasks for a novel design SCBA: effect of weight, volume and weight distribution. Applied ergonomics, 34(2), 157-165.

Hsiao, H, Whitestone, J, Kau, TY, Whisler, R, Routley, JG, \& Wilbur, M. (2014). Sizing Firefighters method and implications. Human Factors: The Journal of the Human Factors and Ergonomics Society, doi:10.1177/0018720813516359.

Helneman, EF, Shy, CM, \& Checkoway, H. (1989). Injuries on the fireground: risk factors for traumatic injuries among professional fire fighters. American Journal of Industrial Medicine, 15(3), 267-282.

Huck, J. (1988). Protective clothing systems: a technique for evaluating restriction of wearer mobility. Applied ergonomics, 19(3), 185-190.

Marshall, SLA. (1980). The Soldier's Load and the Mobility of a Nation. Quantico, Virginia: Marine Corps Association.

Neeves, R, Barlow, DA, Richards, JG, Provost-Craig, M, \& Castagno, P. (1989). Physiological and Biomechanical Changes in Fire Fighters Due to Boot Design Modifications. International Association of Fire Fighters and the Federal Emergency Management Agency.

Park, H, Branson, D, Petrova, A, Peksoz, S, Goad, C, Warren, A, Jacobson, B, \& Kamenidis, P. (2013). Effects of body armor and load carriage on lower limb joint movement. Journal of Human Performance in Extreme Environments, 10(2), 3. doi:http://dx.doi.org/10.7771/2327-2937.1049.

Park, K, Hur, P, Rosengren, KS, Horn, GP, \& Hsiao-Wecksler, ET. (2010). Effect of load carriage on gait due to firefighting air bottle configuration. Ergonomics, 53(7), 882-891.

Sinden, K, MacDermid, J, Buckman, S, Davis, B, Matthews, T, \& Viola, C. (2013). A qualitative study on the experiences of female firefighters. Work: A Journal of Prevention, Assessment and Rehabilitation, 45(1), 97-105.

Sobeih, TM, Davis, KG, Succop, PA, Jetter, WA, \& Bhattacharya, A. (2006). Postural balance changes in on-duty firefighters: effect of gear and long work shifts. Journal of Occupational and Environmental Medicine, 48(1), 68-75.

Taylor, NAS, Lewis, MC, Notley, SR, \& Peoples, GE. (2011). The Oxygen Cost of Wearing Firefighters' Personal Protective Equipment: Ralph Was Right! In S Kounalakis \& M Koskolou (Eds.), ICEE 2011 XIV International Conference on Environmental Ergonomics: Book of Abstracts (pp. 236-239). Athens: National and Kapodestrian University of Athens.

doi:10.1186/s40691-014-0008-3

Cite this article as: Park et al.: Assessment of Firefighters' needs for personal protective equipment. Fashion and Textiles 2014 1:8.

\section{Submit your manuscript to a SpringerOpen ${ }^{\circ}$ journal and benefit from:}

- Convenient online submission

- Rigorous peer review

- Immediate publication on acceptance

- Open access: articles freely available online

- High visibility within the field

Retaining the copyright to your article

Submit your next manuscript at $\boldsymbol{\Delta}$ springeropen.com 